\title{
ESTRATÉGIAS DE MARKETING ESPORTIVO DE CLUBES DE FUTEBOL DO AGRESTE PERNAMBUCANO
}

Anna Rebeca do Nascimento Bezerra Graduada em Administração

Universidade Federal de Pernambuco annarebeca06@hotmail.com

Mario Rodrigues dos Anjos Neto Mestre em Administração

Universidade Federal de Pernambuco mariodosanjosneto@gmail.com

\section{Resumo}

Patrícia de Oliveira Campos

Graduada em Administração

Universidade Federal de Pernambuco patriciadeocampos@gmail.com

Marconi Freitas da Costa Doutor em Administração Universidade Federal de Pernambuco marconi.fcosta@ufpe.br

Objetivo do estudo: Pretendeu-se por meio deste estudo demonstrar como é realizado o marketing esportivo pelos times do Agreste de Pernambuco.

Metodologia/abordagem: Para esta pesquisa, adotou-se uma abordagem qualitativa, na qual o corpus foi interpretado por meio da análise de conteúdo.

Originalidade/relevância: As pesquisas acerca do tema em pauta têm sido desenvolvidas em sua maioria no Sul e Sudeste do Brasil, sendo de natureza quantitativa. Além disso, as estratégias adotadas por clubes locais do marketing esportivo ainda são incipientes na literatura. Por isso, busca-se contribuir ao campo científico do marketing esportivo ao analisar os clubes de um contexto local, mas com trajetória consolidada. Principais resultados: Foi possível notar que o setor de marketing esportivo dos clubes do Agreste Pernambucano ainda se encontra incipiente, especialmente porque eles adotam estratégias limitadas de marketing, apesar de possuírem uma longa trajetória.

Contribuições teóricas/metodológicas: Destaca-se como uma das principais contribuições teóricas a exposição da realidade de clubes de futebol que estão à margem dos principais centros futebolísticos do Brasil. Embora esse cenário seja pouco discutido na academia, ele é relevante para o futebol brasileiro. Evidencia-se, nesse sentido, que, apesar de a literatura apontar a figura do fã como central para o marketing esportivo, na realidade estudada o foco reside nos patrocinadores. Diante disso, a relação clube-torcedor parece não ser o foco das estratégias adotadas pelos clubes, mas sim a relação clube-patrocinador.

Contribuições sociais/para a gestão: Destaca-se como forma de maximizar as receitas dos clubes a utilização de metodologias de gestão de relacionamento com o cliente a fim de prover estratégias que visem o alcance dos fãs para os reter e atrair novos.

Palavras-chave: Marketing esportivo. Clubes esportivos. Futebol. Clubes de futebol de Pernambuco.

\section{$\underline{\text { Cite como }}$}

American Psychological Association (APA)

Bezerra, A. R. N., Anjos Neto, M. R., Campos, P. O., \& Costa, M. F. (2021, set./dez.). Estratégias de marketing esportivo de clubes de futebol do Agreste Pernambucano. PODIUM Sport, Leisure and Tourism Review, São Paulo, 10(3), 1-20. https://doi.org/10.5585/podium.v10i3.16578. 
Bezerra, A. R. N., Anjos Neto, M. R., Campos, P. O., \& Costa, M. F. (2021, set./dez.). Estratégias de marketing Esportivo de clubes de futebol do Agreste Pernambucano

\section{SPORTS MARKETING STRATEGIES OF SOCCER CLUBS FROM AGRESTE OF PERNAMBUCO}

Purpose: We aimed to demonstrate how sports marketing is performed by the teams from the Agreste region of Pernambuco.

Methodology/approach: A qualitative approach was adopted, in which the corpus was interpreted in light of content analysis.

Originality/relevance: Studies on sports marketing have been developed chiefly in the South and Southeast of Brazil, being of a quantitative nature. In addition, the strategies adopted by local sports marketing clubs are still in their infancy in the literature. Therefore, we seek to contribute to the scientific field of sports marketing by analysing clubs from a local context but with a consolidated trajectory.

Main results: We noticed the clubs' sports marketing sector of Agreste Pernambucano is still incipient, especially since they adopt limited marketing strategies, even though they have a long history.

Theoretical/methodological contributions: We stand out the main theoretical contributions as the exposure of soccer clubs on the margins of the leading soccer centres in Brazil. Although this scenario is little discussed in the academy, it is relevant to Brazilian soccer. Even though the literature points to the fan as central to sports marketing strategies, the focus lies on the sponsors in the studied reality. Therefore, the club-fan relationship does not seem to be the clubs' strategies' focus but rather the clubsponsor relationship.

Social/management contributions: We highlight that a way to maximise the clubs' revenues is adopting customer relationship management methodologies to provide strategies that reach the fans to retain them and attract new ones.

Keywords: Sports marketing. Sports clubs. Soccer. Soccer clubs of Pernambuco.

\section{ESTRATEGIAS DE MARKETING DEPORTIVO PARA CLUBES DE FÚTBOL EN AGRESTE PERNAMBUCANO}

Objetivo: Este estudio tuvo como objetivo demostrar cómo los equipos de Agreste de Pernambuco llevan a cabo el Marketing Deportivo.

Metodología/enfoque: Para esta investigación se adoptó un enfoque cualitativo, en el cual se interpretó el corpus a partir del análisis de contenido.

Originalidad/relevancia: La investigación sobre el tema que nos ocupa se há desarrollado principalmente en el sur y sureste de Brasil, siendo de carácter cuantitativo. Además, las estrategias adoptadas por los clubes de marketing deportivo locales son aún incipientes en la literatura. Por ello, buscamos contribuir al campo científico del marketing deportivo mediante el análisis de clubes en un contexto local, pero con una trayectoria consolidada.

Principales resultados: Se pudo notar que el sector de marketing deportivo de los clubes de Agreste Pernambucano es aún incipiente, sobre todo porque adoptan estrategias de marketing limitadas, a pesar de tener una larga trayectoria.

Aportes teórico/metodológicos: Una de las principales aportaciones teóricas es la exposición de la realidad de los clubes de fútbol que se encuentran al margen de los principales centros futbolísticos de Brasil. Aunque este escenario es poco discutido en la academia, es relevante para el fútbol brasileño. Es evidente, en este sentido, que si bien la literatura apunta a la figura del aficionado como eje central del marketing deportivo, en la realidad estudiada el foco está en los patrocinadores. Por tanto, la relación club-afición no parece formar parte del alcance de las estrategias de los clubes, sino más bien del clubpatrocinador.

Contribuciones sociales/de gestión: El uso de metodologías de gestión de relaciones con los clientes con el fin de proporcionar estrategias destinadas a llegar a los aficionados para retenerlos y atraer nuevos se destaca como una forma de maximizar los ingresos del club.

Palabras clave: Marketing deportivo. Clubes deportivos. Fútbol. Clubes de fútbol de Pernambuco. 
Bezerra, A. R. N., Anjos Neto, M. R., Campos, P. O., \& Costa, M. F. (2021, set./dez.). Estratégias de marketing Esportivo de clubes de futebol do Agreste Pernambucano

\section{Introdução}

O futebol é um emblema do Brasil e representa uma parte significativa de influência no desenvolvimento econômico, político e social do país (Costa et al., 2018). As organizações de fins lucrativos o observam como um investimento ao buscarem por estratégias para conectar suas marcas a determinados times e, assim, promover seus produtos - bens, serviços e/ou experiências - e a sua autoimagem (Fortunato, 2017). O marketing esportivo se caracteriza como uma dessas estratégias.

Cabe destacar que o marketing esportivo é definido em duas perspectivas. A primeira se refere ao marketing do esporte, o qual pode ser compreendido como um meio de atender às expectativas dos consumidores mediante a oferta de produtos de cunho esportivo (Mullin, Hardy \& Sutton, 2007). Por seu turno, a segunda está relacionada ao marketing no esporte. Essa última, ou seja, marketing no esporte, em particular, pode ser delimitada enquanto uma ferramenta de promoção utilizada pelas organizações de fins lucrativos (Rocha \& Bastos, 2011). A diferença do marketing no esporte para o marketing tradicional é a possibilidade de promoção da autoimagem isocronicamente à promoção do produto esportivo, como também à disseminação das características e valores da marca (Chun et al., 2013; Fullerton \& Merz, 2008).

Os benefícios das estratégias voltadas ao esporte são inúmeros, principalmente no que tange ao fomento do turismo (Melo Neto, 2000). Apesar das vantagens, em Pernambuco e especialmente na região Agreste do Estado, o que se percebe é uma precariedade no que tange ao marketing esportivo, pois parece não estar se desenvolvendo de forma proporcional às regiões Sul e Sudeste do Brasil. Apesar dos esforços, parece que os times da região pouco têm investido nessa área, que visa o fortalecimento da marca do clube, desperdiçando novas oportunidades de renda e crescimento. Isso porque as estratégias de marketing proporcionariam vantagem competitiva e meios para potencializar os retornos monetários (Reale \& Dalmoro, 2019).

Entende-se que as dificuldades enfrentadas por esses clubes poderiam ser minimizadas mediante um planejamento estratégico de gestão do esporte, mais especificamente na dimensão do marketing, haja vista que esse mercado movimenta no país, aproximadamente, 53 bilhões de reais, tendo $0,72 \%$ de impacto no Produto Interno Bruto - PIB (CBF, 2019). Apesar da relevância da indústria esportiva para as organizações e, majoritariamente, para o Brasil, o seu 
Bezerra, A. R. N., Anjos Neto, M. R., Campos, P. O., \& Costa, M. F. (2021, set./dez.). Estratégias de marketing Esportivo de clubes de futebol do Agreste Pernambucano

campo científico ainda se encontra incipiente e tem se desenvolvido morosamente (Bastos, 2016; Fink, 2013).

Não obstante, a maioria das pesquisas no campo da gestão do esporte utiliza uma abordagem quantitativa (Santos, Freire, \& Miranda, 2017), as quais não exploram em profundidade contexto locais a fim de prover uma visão mais detalhada do fenômeno. Há, nesse sentido, uma necessidade do desenvolvimento de estudos com enfoque qualitativo que visem aprofundar as peculiaridades do marketing do esporte. Por esse motivo, busca-se por meio desta pesquisa analisar em profundidade por meio de múltiplos casos como se dá o marketing do esporte por clubes de futebol consolidados do Agreste de Pernambuco.

Para tanto, conduziu-se uma pesquisa com abordagem qualitativa, que se encontra estruturada da seguinte forma: além desta introdução, tem-se a seção do referencial teórico, na qual discutiu-se os pressupostos centrais do marketing esportivo, passando por suas linhas teóricas. Apresenta-se, ainda, uma terceira seção com os procedimentos metodológicos adotados. Na sequência, uma seção com os resultados e discussões e, por fim, destaca-se as conclusões do estudo.

\section{Marketing esportivo}

Dada a emergência da demanda por gestores de esporte especializados, tem-se, a partir da década de 1960, o desenvolvimento da gestão do esporte enquanto campo científico (Rocha \& Bastos, 2011). No limiar do seu processo de consolidação, esse campo emergente possuía como base teórica livros que endereçavam a educação física e atletas (Pitts, 2001). Com o avançar das discussões, os pesquisadores do campo começaram a incorporar teorias advindas da área da Administração (Rocha \& Bastos, 2011). Diante disso, os termos gestão do esporte e administração do esporte passam a ser utilizados na literatura (Chelladurai, 2009). Cabe salientar, entretanto, que, apesar dos contrassensos, não há distinção entre gestão e administração do esporte, sendo gestão do esporte o termo preferido para designar a área (Rocha \& Bastos, 2011).

Vale ressaltar, ainda, que não há um consenso no que tange às atividades da gestão do esporte, pois, por um lado, defende-se que envolve a gestão do esporte em si, por outro, tem-se uma visão mais holística de que se refere a gerenciar todas as práticas da indústria do esporte (Pitts, 2001). Essas disparidades decorrem, dentre outros aspectos, do próprio processo de consolidação da temática enquanto campo científico. As pesquisas seminais tinham como base 
Bezerra, A. R. N., Anjos Neto, M. R., Campos, P. O., \& Costa, M. F. (2021, set./dez.). Estratégias de marketing Esportivo de clubes de futebol do Agreste Pernambucano

os métodos e teorias do campo da gestão, o que tornou a consolidação das bases teóricas do campo um alvo de críticas (Zeigler, 1987). É por isso que o arcabouço conceitual da gestão do esporte perpassa por teorias organizacionais, turismo e, sobretudo, pela área de Marketing (Ciomaga, 2013).

Não por acaso, a disciplina de marketing foi uma das primeiras a ser incorporada aos debates da gestão do esporte (Manoli, 2018). Inicialmente, na perspectiva de Parkhouse e Ulrich (1979), por exemplo, o marketing na gestão do esporte atuava como uma mera ferramenta para promovê-lo. É sob esse prisma que mais tarde Mullin (1983) distingue a perspectiva do marketing em três dimensões, a saber: marketing como estratégia para promover o engajamento dos fãs, entusiasmo e o consumo de bens e serviços. Com o avanço das discussões, Chacko e Wagers (1999) resgatam os princípios conceituais do marketing a fim de consolidar o que, de fato, seria o marketing esportivo. Para eles, o arcabouço operacional do marketing esportivo é semelhante a outros segmentos do marketing.

Conforme Chacko e Wagers (1999), os princípios básicos do marketing de bens e serviços também ancoram o marketing do esporte no que tange ao tradicional mix de marketing, que envolve preço, praça, produto e promoção, além de posicionamento e segmentação. Contudo, ainda conforme os autores, o que distingue o marketing do esporte de outras modalidades é a essência do que ele promove, que se traduz em formas tangíveis e intangíveis. Esses formatos se tornam alvo de organizações que buscam patrocinar eventos na tentativa de exercer suas estratégias de marketing por meio do esporte.

Há de se deixar claro que o marketing no esporte, determinado pela prática de organizações não esportivas (Rocha \& Bastos, 2011), é diferente do marketing esportivo desempenhado com fins a promover o esporte em si. Conforme distinções iniciais, o marketing do esporte é um processo pelo qual há, paralelamente, a junção de aspirações de organizações esportivas e demais stakeholders, como clientes e patrocinadores (Chadwick, 2005). De forma mais precisa, Mullin, Hardy e Sutton (2007) o definem como um meio de atender aos consumidores ao ofertar produtos, que atendam às suas expectativas.

A visão do marketing esportivo enfatiza, portanto, o empenho de organizações esportivas e o papel do fã enquanto elemento chave, uma vez que se entende que sua atuação transcende a perspectiva de lealdade do marketing tradicional (Tsiotsou, 2016). Conforme o autor, há de se notar que o marco inicial envolve, ainda, a lógica do produto dominante. Isso porque a organização esportiva é uma ofertante de bens e serviços. O seu produto central - o esporte - é de alcance global, o qual tem o potencial de engajar consumidores das mais 
Bezerra, A. R. N., Anjos Neto, M. R., Campos, P. O., \& Costa, M. F. (2021, set./dez.). Estratégias de marketing Esportivo de clubes de futebol do Agreste Pernambucano

diversas partes do mundo, seja participando ativamente ou em caráter contemplativo (Ratten \& Ratten, 2011). Conforme esse mesmo estudo, essa é a razão pela qual os profissionais de marketing esportivo não atuam com uma visão local, mas numa perspectiva de inserção no mercado internacional.

Um dos tipos de esporte que tem tal alcance mundial e atua nessa perspectiva internacional é o futebol. Ele é de acesso globalizado e proporciona não só valor aos clubes, mas acesso a profissionais qualificados, o que aumenta, em uma visão de médio e longo prazo, as suas receitas (Haugaasen \& Jordet, 2012). Essa modalidade de esporte é um aspecto cultural na esfera do consumo (McDonagh, 2017) e, por isso, os fãs são os principais stakeholders de organizações esportivas (Reale \& Dalmoro, 2019). Numa perspectiva econômica, são as associações entre clubes de futebol e fãs, por exemplo, que geram suas receitas; logo, uma negligência deles por parte dos profissionais de marketing esportivo poderia, na melhor das hipóteses, afastar o seu empenho em apoiar o clube (Liang, 2017).

No contexto do Brasil, a situação econômica dos clubes de futebol pode ser um reflexo da falta de empenho e engajamento com os fãs. Isso porque há uma incapacidade gerencial por parte dos profissionais de marketing esportivo no planejamento estratégico dos clubes (Dabscheck, 2015). Conforme o ensaio teórico do autor, as receitas dos clubes se depreendem sobremaneira da venda de jovens atletas, o que torna o empenho de engajar todas as partes interessadas, incluindo os fãs, em resultados inócuos. É sob essa perspectiva que se busca por meio deste estudo contribuir à literatura ao analisar como se dá o marketing esportivo por clubes de futebol consolidados em um contexto local.

\section{Percurso metodológico}

Para atender ao objetivo central deste estudo, foi adotada uma abordagem de natureza qualitativa, sendo caracterizada por ser exploratória descritiva (Gil, 2002). Segundo Gil (2002, p. 42) "as pesquisas descritivas têm como objetivo primordial a descrição das características de determinada população ou fenômeno". Adotou-se, ainda, a exploração de múltiplos casos de estudo, possibilitando, assim, uma exploração mais profunda do fenômeno em análise (Yin, 2005). Yin (2005) argumenta que o estudo de caso permite conhecer em profundidade aspectos relevantes e idiossincrasias do aspecto ontológico do estudo permitindo ao pesquisador compreender melhor as organizações em análise. 
Bezerra, A. R. N., Anjos Neto, M. R., Campos, P. O., \& Costa, M. F. (2021, set./dez.). Estratégias de marketing Esportivo de clubes de futebol do Agreste Pernambucano

O estudo é considerado de corte seccional simples - transversal - , uma vez que a coleta de dados ocorreu em um único momento (Gil, 2002). Elaborou-se como instrumento de coleta de dados um roteiro de entrevista semiestruturado. A técnica de coleta de dados adotada foi de entrevista em profundidade, na qual os respondentes foram abordados individualmente. O roteiro de entrevista foi montado com base no arcabouço teórico do marketing esportivo a fim de identificar, por exemplo, a conceituação de marketing esportivo pelos entrevistados, principais estratégias adotadas tanto internas como com os stakeholders. Os eixos utilizados para guiar as entrevistas podem ser visualizados no Quadro 1.

\section{Quadro 1}

\section{Eixos Utilizados no Roteiro de Entrevista}

\begin{tabular}{|c|c|c|}
\hline Eixos & Descrição & Base teórica \\
\hline $\begin{array}{l}\text { Conceito de Marketing } \\
\text { Esportivo. }\end{array}$ & $\begin{array}{l}\text { Indagou-se sobre qual a conceituação } \\
\text { atribuída ao marketing do esporte pelos } \\
\text { diretores dos clubes participantes da pesquisa. }\end{array}$ & $\begin{array}{l}\text { Chacko e Wagers (1999); } \\
\text { Chadwick (2005); Mullin, } \\
\text { Hardy e Sutton (2007). }\end{array}$ \\
\hline $\begin{array}{l}\text { Importância do Marketing } \\
\text { Esportivo. }\end{array}$ & $\begin{array}{c}\text { Foi questionado acerca da percepção da } \\
\text { contribuição e relevância do marketing } \\
\text { esportivo na gestão dos clubes. }\end{array}$ & $\begin{array}{l}\text { Mullin, Hardy e Sutton } \\
\text { (2007); Liang (2017). }\end{array}$ \\
\hline $\begin{array}{l}\text { Utilização da Pesquisa de } \\
\text { Mercado. }\end{array}$ & $\begin{array}{l}\text { Foram realizadas perguntas sobre a condução } \\
\text { de pesquisas de mercado para identificar as } \\
\text { expectativas de torcedores; as necessidades } \\
\text { dos funcionários - inclusive de jogadores - } \\
\text { dos clubes; os pontos fortes e fracos de } \\
\text { adversários na modalidade futebol } \\
\text { profissional; os pontos fortes e fracos de seus } \\
\text { adversários para outras modalidades } \\
\text { esportivas; e, ainda, os pontos fortes e fracos } \\
\text { dos adversários para captar e reter torcedores. }\end{array}$ & $\begin{array}{l}\text { Chelladurai (2009); Mullin, } \\
\text { Hardy e Sutton (2007); Rocha } \\
\text { e Bastos (2011). }\end{array}$ \\
\hline $\begin{array}{l}\text { Compreensão acerca da } \\
\text { forma de gestão do clube. }\end{array}$ & $\begin{array}{l}\text { Foi indagado sobre como ocorre a gestão dos } \\
\text { clubes, sinalizando, em especial, sua } \\
\text { estruturação, tomada de decisões e nível de } \\
\text { especialização profissional dos membros. }\end{array}$ & $\begin{array}{c}\text { Chelledurai (2009); } \\
\text { Dabscheck (2015); Rocha e } \\
\text { Bastos (2011). }\end{array}$ \\
\hline $\begin{array}{l}\text { Principais fontes de renda } \\
\text { do clube. }\end{array}$ & $\begin{array}{c}\text { Questionamento acerca dos principais meios } \\
\text { pelos quais os clubes captam recursos } \\
\text { financeiros. }\end{array}$ & $\begin{array}{l}\text { Dabscheck (2015); Liang } \\
\text { (2017). }\end{array}$ \\
\hline $\begin{array}{l}\text { Estratégias de } \\
\text { fortalecimento do futebol } \\
\text { profissional. }\end{array}$ & $\begin{array}{l}\text { Pergunta sobre as estratégias criadas pelos } \\
\text { clubes para fortalecer o futebol profissional. }\end{array}$ & $\begin{array}{l}\text { Dabscheck (2015); Reale e } \\
\text { Dalmoro (2019). }\end{array}$ \\
\hline $\begin{array}{c}\text { Estratégias relacionadas a } \\
\text { marcas. }\end{array}$ & $\begin{array}{l}\text { Indagações acerca da forma de gestão de } \\
\text { marca pelos clubes. }\end{array}$ & Chadwick (2005). \\
\hline $\begin{array}{l}\text { Estratégias de } \\
\text { comunicação. }\end{array}$ & $\begin{array}{l}\text { Perguntas acerca de como os clubes } \\
\text { estabelecem comunicações com os torcedores, } \\
\text { os sócios e o público em geral. }\end{array}$ & $\begin{array}{l}\text { Liang (2017); Rocha e Bastos } \\
\text { (2011). }\end{array}$ \\
\hline $\begin{array}{l}\text { Estratégia de } \\
\text { relacionamento com os } \\
\text { sócios. } \\
\end{array}$ & $\begin{array}{l}\text { Questões para identificar se há gestão de } \\
\text { relacionamento com os sócios e, em caso } \\
\text { positivo, como ela ocorre. }\end{array}$ & $\begin{array}{l}\text { Chadwick (2005); Reale e } \\
\text { Dalmoro (2019). }\end{array}$ \\
\hline
\end{tabular}

Fonte: Elaboração própria, 2021. 
Bezerra, A. R. N., Anjos Neto, M. R., Campos, P. O., \& Costa, M. F. (2021, set./dez.). Estratégias de marketing Esportivo de clubes de futebol do Agreste Pernambucano

Conforme se pretendeu analisar a perspectiva dos responsáveis pelo marketing esportivo dos clubes, identificou-se na incursão em campo que os atuantes na função do marketing esportivo não atuam necessariamente apenas na área de Marketing ou são especialistas na temática. Isso porque os respondentes foram um Diretor de Marketing, Diretor de Futebol e um Diretor Administrativo. É válido destacar que os clubes foram escolhidos em razão de terem uma trajetória longa e consolidada no esporte. Com o intuito de preservar o anonimato dos participantes, foram adotados nomes fictícios para os clubes, quais sejam: Clube A, Clube B e Clube C.

Os três clubes são de cidades pequenas. O Clube A foi fundado em 1919. Ele já foi campeão brasileiro da série B e duas vezes vice-campeão pernambucano. Além disso, ele possui 657 sócios e 9 patrocinadores. Ele oferta 5 planos no escopo do seu programa de sócio-torcedor, os quais possuem uma taxa anual. O plano com o valor maior possibilita o acesso livre à arquibancada social do estádio do clube, garante o direito a voto nas decisões eleitorais do clube, como também um dependente do sócio possui desconto na compra de ingressos. Essa última característica é o que diferencia o plano de maior valor para o plano com o menor valor imediato. Há, ainda, um plano exclusivo para mulheres, o qual, seguindo a ordem de preços, possui as mesmas características do plano subsequente: desconto e prioridade na compra de ingressos, carteirinha de sócio e acesso ao clube parceiro. Por fim, o plano básico possibilita acesso ao clube parceiro, carteirinha e desconto na compra de itens oficiais do clube.

Por seu turno, o Clube B iniciou sua história em 1993 e já foi vice-campeão pernambucano dois anos consecutivos. Além disso, já participou da Copa do Brasil e da Copa do Nordeste. O clube não possui programas de sócio-torcedor e, portanto, não possui sócios. Ele conta com o apoio de 14 patrocinadores. Quanto ao Clube C, ele começou sua trajetória em 1938. Ele foi campeão pernambucano na segunda divisão e já disputou a $3^{\text {a }}$ divisão do Campeonato Brasileiro. O clube possui um plano anual para os sócios, o qual, por meio do pagamento de uma taxa, fornece acesso antecipado a camisas oficiais e ingressos para jogos. Os três clubes possuem uma torcida pequena quando comparados a times do Nordeste de maior destaque. No entanto, em termos de comparação, o Clube A possui a maior torcida.

Seguindo-se o delineamento metodológico, destaca-se que foram realizadas três entrevistas semiestruturadas com os três diretores dos clubes de futebol. A duração das entrevistas foi de: Diretor de Marketing do Clube A (31min36s), Diretor de Futebol do Clube B (34min31s), Diretor do clube C (59min7s). A transcrição das entrevistas resultou em um corpus composto por 30 páginas, fonte Times New Roman, tamanho 12. O corpus foi analisado 
Bezerra, A. R. N., Anjos Neto, M. R., Campos, P. O., \& Costa, M. F. (2021, set./dez.). Estratégias de marketing Esportivo de clubes de futebol do Agreste Pernambucano

com base na análise de conteúdo (Bardin, 1977). Seguindo as etapas que indica a autora, realizou-se: pré-análise, codificação, categorização, análise e interpretação.

Inicialmente, conduziu-se a etapa de pré-análise, que corresponde à análise inicial dos trabalhos. Ela se caracteriza pelas decisões que o pesquisador deverá tomar em relação à problematização, aos objetivos, às formulações de conjecturas e/ou questões centrais e secundárias, a seleção dos textos e da amostra, bem como a revisão de literatura para uma melhor captação do assunto objeto da pesquisa (Bardin, 1977). Nesse momento, buscou-se realizar um levantamento bibliográfico do tipo desk research, permitindo uma maior compreensão sobre as organizações objetos do estudo e da temática em análise. Em seguida, a leitura flutuante do corpus foi realizada, sendo possível criar categorias ao longo das leituras.

Numa segunda etapa, foi realizada a codificação, isto é, a determinação da unidade de análise, que corresponde aos elementos básicos do texto que viabilizarão a classificação das informações coletadas em categorias. Essa etapa consiste na transformação dos dados brutos do texto, permitindo, assim, uma representação do conteúdo. No presente estudo, seguindo as orientações de Bardin (1977), atribuiu-se destaque à palavra, ao tema e ao documento com o objetivo de estabelecer associações entre esses e a temática por meio da identificação de núcleos de sentido - conexões entre os documentos coletados e o assunto analisado. Desse modo, nessa fase, buscou-se identificar trechos ou citações que representavam tais relações.

Na sequência, realizou-se a categorização, que é considerada a fase mais relevante de todo o processo. Essa etapa consiste na classificação dos elementos de análise - conteúdo das entrevistas - em categorias. Uma categorização mal elaborada comprometeria os resultados da análise de conteúdo. Para assegurar a categorização adequada, considerou-se indispensável uma revisão de literatura extensa e profunda sobre o tema em pauta (Bardin, 1977). Neste trabalho, adotou-se categorias existentes (Quadro 1), uma vez que se constata uma literatura abrangente sobre marketing esportivo e desejava-se comparar o conteúdo das entrevistas com tais categorias, denominadas nesta pesquisa de eixos. Por fim, as análises e interpretações foram realizadas. Nessa etapa surgem as conclusões acerca do material coletado. No presente estudo, expôs-se o conteúdo das entrevistas dos três diretores com as divisões baseadas na literatura sobre o tema. 
Bezerra, A. R. N., Anjos Neto, M. R., Campos, P. O., \& Costa, M. F. (2021, set./dez.). Estratégias de marketing Esportivo de clubes de futebol do Agreste Pernambucano

\section{Análise e discussão dos resultados}

\subsection{Eixo temático I: Conceito de marketing esportivo}

\section{Quadro 2}

Percepções dos Respondentes Acerca do Conceito de Marketing Esportivo

\begin{tabular}{|c|c|}
\hline $\begin{array}{c}\text { Compreensão do } \\
\text { Conceito de Marketing } \\
\text { Esportivo }\end{array}$ & "[...] é tudo aquilo que você trabalha com o produto do clube" (Diretor de Marketing \\
do Clube A).
\end{tabular}

Fonte: Dados da pesquisa.

Conforme é possível observar, o diretor de marketing esportivo do Clube A relata uma definição que corrobora com o delineado por Chacko e Wagers (1999) e Mullin, Hardy e Sutton (2007). Isso porque toca no elemento central que distingue o marketing tradicional do marketing esportivo, isto é, o produto esportivo. Logo, os empenhos realizados em torno do produto tangível ou intangível - como uma forma de o tornar disponível caracteriza as ações empregadas pelo responsável do marketing do esporte. A visão do diretor de futebol do Clube B, por sua vez, demonstra uma perspectiva limitada, visto que parece associar o marketing esportivo apenas à promoção. Academicamente, sabe-se que ele vai muito além do uso apenas de meios de promoção, pois envolve também preço, produto, praça, posicionamento e segmentação (Chacko \& Wagers, 1999).

No que tange à definição do diretor administrativo do Clube $\mathrm{C}$, observa-se o marketing esportivo como um conjunto de elementos que são subjacentes às atividades do clube, visto que as destaca enquanto ferramentas auxiliares. Isso toca nas discussões seminais acerca do marketing esportivo, uma vez que era interpretado apenas como um meio de promover o esporte (Parkhouse \& Ulrich, 1979). Apesar dos avanços quanto ao entendimento do papel elementar do marketing esportivo no conjunto de atividades da gestão do esporte, o diretor do Clube $\mathrm{C}$ ainda parece não ter clara essa definição. 
Bezerra, A. R. N., Anjos Neto, M. R., Campos, P. O., \& Costa, M. F. (2021, set./dez.). Estratégias de marketing Esportivo de clubes de futebol do Agreste Pernambucano

\subsection{Eixo temático II: Importância do marketing esportivo}

Quadro 3

Percepção a Respeito da Importância do Marketing Esportivo

\begin{tabular}{|c|c|}
\hline \multirow{3}{*}{$\begin{array}{l}\text { Compreensão acerca } \\
\text { da contribuição do } \\
\text { Marketing Esportivo }\end{array}$} & $\begin{array}{c}\text { "[...] o marketing foi quem mais arrecadou dinheiro nos últimos dois anos [...] com } \\
\text { a venda de propaganda na camisa do clube, vários patrocinadores..." (Diretor de } \\
\text { Marketing do Clube A). }\end{array}$ \\
\hline & $\begin{array}{l}\text { "[...] marketing também é uma coisa que atrai recursos divisas" (Diretor de Futebol } \\
\text { do Clube B). }\end{array}$ \\
\hline & $\begin{array}{c}\text { "[...] marketing esportivo [...] consegue ofertar produtos e captar receita" (Diretor } \\
\text { do Clube C). }\end{array}$ \\
\hline
\end{tabular}

Fonte: Dados da pesquisa.

O diretor de marketing esportivo do Clube A destaca o marketing do esporte como elementar para gerar recursos monetários. A definição dele apresenta um olhar estratégico quanto aos stakeholders, principalmente no tange aos patrocinadores. Isso se alinha ao que Chadwick (2005) destaca em relação ao processo do marketing esportivo, o qual é envolto pela junção de objetivos das organizações esportivas e não esportivas. O diretor de futebol do Clube B também entende a relevância do marketing esportivo para atrair recursos. Alinhando-se a uma definição mais próxima do que já aborda a literatura, o diretor do clube $\mathrm{C}$ destaca a função do marketing não apenas como um meio para gerar receitas, mas também como uma ferramenta para ofertar os produtos.

Observa-se mediante as perspectivas dos três diretores que o papel do marketing esportivo para promover uma relação entre o fã e o clube parece ser negligenciada. Isso demonstra uma visão limitada, haja vista que o marketing do esporte se orienta à associação entre produtor-consumidor; logo, volta-se para atender às expectativas dos consumidores (Mullin, Hardy, \& Sutton, 2007). Conforme a visão do diretor de marketing do Clube A, o foco do marketing esportivo seria a relação clube-patrocinador. Isso vai de encontro ao que destaca Liang (2017), visto que, em termos de receita, os fãs, enquanto stakeholders, é que possuem um papel central. 
Bezerra, A. R. N., Anjos Neto, M. R., Campos, P. O., \& Costa, M. F. (2021, set./dez.). Estratégias de marketing Esportivo de clubes de futebol do Agreste Pernambucano

\subsection{Eixo temático III: Utilização da pesquisa de mercado}

Quadro 4

Critérios de Uso da Pesquisa de Mercado

\begin{tabular}{|c|c|}
\hline \multirow{3}{*}{$\begin{array}{c}\text { Condições de } \\
\text { utilização da Pesquisa } \\
\text { de Mercado }\end{array}$} & $\begin{array}{c}\text { "[...] precisa investir mais [...] se espelhar principalmente nas coisas que estão } \\
\text { dando certo" (Diretor de Marketing do Clube A). }\end{array}$ \\
\hline & "[...] a gente identifica que é interessante" (Diretor de Futebol do Clube B). \\
\hline & $\begin{array}{l}\text { "[...] informações é um insumo principal de qualquer planejamento [...] e } \\
\text { informação de qualidade você consegue com pesquisa" (Diretor do Clube C). }\end{array}$ \\
\hline
\end{tabular}

Fonte: Dados da pesquisa.

Nos discursos dos dirigentes foi possível captar a que fim se prestam as pesquisas de mercado para eles. Na perspectiva do Clube A, os dirigentes as utilizam em três situações, a saber: identificar as necessidades dos funcionários, conhecer pontos fortes e fracos de adversários e captar novos torcedores. Isso está em consonância com o que apontam Mullin, Hardy e Sutton (2007) acerca de conhecer as expectativas dos torcedores para poder as atender e, assim, retê-los. Além disso, alinha-se ao que destacam Chelladurai (2009) e Rocha e Bastos (2011) acerca da importância de conhecer a indústria do esporte no sentido de se preparar para a gestão. No Clube B, por seu turno, são realizados dois tipos de pesquisa: para conhecer e atender às necessidades dos funcionários e para identificar também as forças e fraquezas de adversários. Por fim, o Clube C adota a mesma finalidade do Clube B. Contudo, o diretor acredita que é necessário um maior envolvimento com pesquisadores propriamente ditos para que as informações adquiridas sejam de qualidade.

Apesar do reconhecimento da importância das pesquisas de mercado, os diretores reportam que ainda não são executadas como deveriam. Nota-se que apenas na fala do diretor do Clube A é que os torcedores aparecem. Logo, mais uma vez, nota-se que os fãs parecem constituir uma categoria não reconhecida como basilar na ótica dos clubes. Conforme destaca Tsiotsou (2016), o torcedor é o elemento central, dado que sua atuação transcende a perspectiva de lealdade quando inserido no esporte. Um dos pontos convergentes entre as estratégias dos clubes é focar em identificar os pontos fortes e fracos de adversários. Nesse sentido, para eles, percebe-se que a pesquisa de mercado tem uma função de garantir que os clubes não estejam em desvantagem quanto aos oponentes e como forma de obter informações quanto às fraquezas para conseguir, assim, vantagem competitiva. 
Bezerra, A. R. N., Anjos Neto, M. R., Campos, P. O., \& Costa, M. F. (2021, set./dez.). Estratégias de marketing Esportivo de clubes de futebol do Agreste Pernambucano

\subsection{Eixo temático IV: Compreensão acerca da forma de gestão do clube}

\section{Quadro 5}

\section{Entendimento dos Dirigentes Acerca da Gestão do Clube}

\begin{tabular}{|c|c|}
\hline \multirow{3}{*}{$\begin{array}{l}\text { Compreensão dos } \\
\text { dirigentes acerca da } \\
\text { forma de Gestão do } \\
\text { Clube }\end{array}$} & $\begin{array}{c}\text { "[...] o conselho administra e fiscaliza tudo que o executivo realiza" (Diretor de } \\
\text { Marketing do Clube A). }\end{array}$ \\
\hline & $\begin{array}{c}\text { "[...] estruturalmente, tem um presidente, uma gerência administrativa e uma } \\
\text { secretária" (Diretor de Futebol do Clube B). }\end{array}$ \\
\hline & $\begin{array}{c}\text { "[...] uma necessidade de rever todo um conceito administrativo [...] para criar um } \\
\text { alicerce" (Diretor do Clube C). }\end{array}$ \\
\hline
\end{tabular}

Fonte: Dados da pesquisa.

No Clube A, a gestão é dividida em duas partes: a executiva, que toma as decisões, composta por presidente, vices e secretário administrativo, e o conselho que fiscaliza as ações do executivo, que basicamente é composto pelos mesmos cargos do executivo. O clube realiza eleições a cada dois anos a fim de decidir estes gestores. O Clube B, por seu turno, é gerido por um presidente, que é auxiliado por uma gerência de futebol e por uma secretária. Diferentemente do Clube A, o Clube B não realiza eleições. Há de se destacar que o diretor do Clube $\mathrm{C}$ acredita que a gestão ainda é muito amadora. Para ele, o modelo de gestão deveria ser revisto a fim de desenvolver melhores alicerces.

Como é possível observar nas falas dos diretores, o Clube A parece ter uma estrutura descentralizada das decisões estratégicas, visto que não reside exclusivamente na tomada de decisão do presidente, o que é o caso do Clube B. A fala do diretor do Clube C revela a necessidade de membros especializados em gestão do esporte no corpo administrativo do clube. Isso corrobora com o apontado por Dabscheck (2015), o qual destaca que, no Brasil, há um déficit quanto a uma gestão eficiente e eficaz nos clubes de futebol.

\subsection{Eixo temático V: Principais fontes de renda do clube}

\section{Quadro 6}

Principais Fontes de Renda

\begin{tabular}{|c|c|}
\hline \multirow{3}{*}{$\begin{array}{l}\text { Principais fontes de renda } \\
\text { do clube }\end{array}$} & $\begin{array}{c}\text { “[...] a principal fonte de renda hoje é o sócio, as lojinhas do estádio, a } \\
\text { participação do governo nos ingressos do torcedor" (Diretor de Marketing do } \\
\text { Clube A). }\end{array}$ \\
\hline & $\begin{array}{l}\text { "[...] o Clube B sobrevive do Campeonato Pernambucano, da renda, televisão, } \\
\text { todos com a nota, algumas propagandas" (Diretor de Futebol do Clube B). }\end{array}$ \\
\hline & $\begin{array}{l}\text { "[...] a principal fonte de renda é o Programa Todos com a Nota do Governo do } \\
\text { Estado, depois você vê parcerias" (Diretor do Clube C). }\end{array}$ \\
\hline
\end{tabular}

Fonte: Dados da pesquisa. 
Bezerra, A. R. N., Anjos Neto, M. R., Campos, P. O., \& Costa, M. F. (2021, set./dez.). Estratégias de marketing Esportivo de clubes de futebol do Agreste Pernambucano

Diferente do que destaca Dabscheck (2015), a principal fonte de renda dos clubes não é relatada como sendo a venda de jovens atletas. Para o diretor do Clube A, as principais fontes de arrecadação são os sócios, o aluguel das lojas que estão na galeria do clube, a renda dos jogos e o Programa Todos com a Nota $(\mathrm{PTN})^{1}$. Os clubes B e C identificaram também o PTN com uma das suas principais fontes de renda, além de elucidar a renda dos jogos, a transmissão pela televisão, publicidade, parcerias com empresas privadas e com órgãos públicos.

Nos três clubes, os torcedores conseguem contribuir para as suas receitas por meio da compra de ingressos e camisas oficiais. Além disso, os programas sócio-torcedor dos Clubes A e C contribuem para a obtenção de receitas, visto que os torcedores realizam o pagamento de uma taxa anual para receberem alguns benefícios, como descontos e acessos antecipados a novos produtos e ingressos. Cabe destacar que apesar da contribuição dos torcedores na geração de receitas para os clubes, o papel deles é pouco enfatizado pelos diretores.

\subsection{Eixo temático VI: Estratégias de fortalecimento do futebol profissional}

\section{Quadro 7}

\section{Estratégias de Fortalecimento do Futebol Profissional}

\begin{tabular}{|c|c|}
\hline \multirow{3}{*}{$\begin{array}{c}\text { Estratégias de } \\
\text { fortalecimento do futebol } \\
\text { profissional }\end{array}$} & $\begin{array}{l}\text { "[...] o principal de tudo é investimento na base de jogadores que estão se } \\
\text { preparando pra ser jogador" (Diretor de Marketing do Clube A). }\end{array}$ \\
\hline & "[...] a estratégia forte é trabalhar a base" (Diretor de Futebol do Clube B). \\
\hline & $\begin{array}{l}\text { "[...] o Clube C sofre mais com isso porque não é só um clube de futebol, tem a } \\
\text { parte social" (Diretor do Clube C). }\end{array}$ \\
\hline
\end{tabular}

Fonte: Dados da pesquisa.

O diretor do Clube A destacou que precisa investir mais na base, haja vista que por meio dela o time estará investindo no seu futuro. O diretor do Clube B também reconhece a importância do trabalho na base. Ele ressalta que o clube utiliza essa estratégia porque o custo acaba sendo menor e, caso o jogador se destaque, proporcionará um grande retorno financeiro. Isso se alinha ao que destaca o artigo conceitual de Dabscheck (2015), pois, embora a principal fonte de renda não seja relatada pelos diretores como a venda de jogadores, há um vislumbre de que essa é uma estratégia de fortalecimento efetiva. Contudo, conforme já destacado pelo autor, isso pode resultar em efeitos reversos ao desencorajar o apoio dos torcedores. No que tange ao dirigente do Clube $\mathrm{C}$, ele não definiu as estratégias do clube. Ele apenas relatou que,

${ }^{1}$ O Programa Todos com a Nota foi desenvolvido pelo Governo de Pernambuco no intuito de conscientizar o consumidor acerca da importância de solicitar a nota fiscal. O programa possibilitava a troca do valor de cupons e notas fiscais por uma pontuação, que poderia ser utilizada para adquirir ingressos para assistir a jogos esportivos (Ferreira \& Leão, 2018). 
Bezerra, A. R. N., Anjos Neto, M. R., Campos, P. O., \& Costa, M. F. (2021, set./dez.). Estratégias de marketing Esportivo de clubes de futebol do Agreste Pernambucano

como trabalha com uma sede social, a estrutura é mais complexa, o que dificulta a administração.

\subsection{Eixo temático VII: Identificar e explicar estratégias relacionadas a marcas}

Quadro 8

Estratégias Relacionadas à Marca

\begin{tabular}{|c|c|}
\hline \multirow{3}{*}{$\begin{array}{c}\text { Estratégias relacionadas a } \\
\text { marcas }\end{array}$} & $\begin{array}{l}\text { "[...] é uma marca forte, uma marca que já tem } 92 \text { anos" (Diretor de Marketing } \\
\text { do Clube A). }\end{array}$ \\
\hline & $\begin{array}{c}\text { "[...] a grande mídia e marca do Clube B chama-se o futebol do Clube B" } \\
\text { (Diretor de Futebol do Clube B). }\end{array}$ \\
\hline & $\begin{array}{l}\text { "[...] eu acho que o clube perde receita por falta de explorar produtos a marca } \\
\text { do clube" (Diretor do Clube C). }\end{array}$ \\
\hline
\end{tabular}

Fonte: Dados da pesquisa.

O diretor do Clube A afirmou que, como o clube existe há 92 anos, possui uma marca consolidada. Eles procuram explorar esse ponto a fim de gerar mais receitas. O Clube B, por sua vez, parece se alicerçar no diferencial de ter um futebol singular, o que fortalece sua marca como o futebol do Clube $\mathrm{B}$. O Clube $\mathrm{C}$ reconhece que perde receita por não trabalhar a marca, pois ela constitui a sua identidade e ajuda o consumidor a distinguir um produto dos demais. Nessa ótica, percebe-se que apenas o Clube A apresenta uma estratégia em torno da marca do clube. Quanto aos Clube B e C, percebe-se que a falta de promoção da própria marca pode resultar em enfraquecimento com seus principais stakeholders, fãs e organizações não esportivas, que buscam se promover por meio do esporte (Chadwick, 2005).

\subsection{Eixo temático VIII: Estratégias de comunicação}

Quadro 9

Estratégias de Comunicação

\begin{tabular}{|l|c|}
\hline \multirow{3}{*}{$\begin{array}{l}\text { Estratégias de } \\
\text { comunicação }\end{array}$} & $\begin{array}{c}\text { "[...] comunicação através de rádios que cobrem o clube no dia-a-dia, além do site } \\
\text { também do clube [...] e da televisão, a cidade tem uma televisão forte, aliás tem } \\
\text { duas, uma faz programa local a outra faz a nível da Capital (Diretor de Marketing } \\
\text { do Clube A). }\end{array}$ \\
\cline { 2 - 2 } & $\begin{array}{c}\text { "[...] o site do clube e a mídia esportiva que cobre o clube e através de e-mails } \\
\text { também, aqueles torcedores que tem e-mail" (Diretor de Futebol do Clube B). }\end{array}$ \\
\cline { 2 - 2 } & $\begin{array}{c}\text { "[...] período do campeonato a gente tem uma aproximação bem maior, } \\
\text { principalmente com o pessoal de rádio e internet" (Diretor do Clube C). }\end{array}$ \\
\hline
\end{tabular}

Fonte: Dados da pesquisa.

Os três clubes - Clube A, Clube B e Clube C - usam os meios de comunicação rádio e internet - para divulgar informações, principalmente durante competições quando a demanda por notícias é maior. O Clube A, em especial, aponta como estratégia de comunicação 
Bezerra, A. R. N., Anjos Neto, M. R., Campos, P. O., \& Costa, M. F. (2021, set./dez.). Estratégias de marketing Esportivo de clubes de futebol do Agreste Pernambucano

o uso da televisão. Esse “uso" se refere, no entanto, ao noticiário veiculado em emissoras locais quanto ao anúncio de jogos e compra de ingressos. Isso demonstra uma estratégia de marketing limitada, tendo em vista que os clubes não possuem controle acerca de como e o que será veiculado. Com efeito, a comunicação pode ser ineficiente, podendo gerar efeitos negativos para os stakeholders, especialmente para os fãs (Liang, 2017).

Cabe destacar, ainda, que o Clube B se comunica não somente pelo sítio eletrônico do clube e pela mídia esportiva, mas também mediante mensagens eletrônicas enviadas aos endereços eletrônicos (e-mails) dos torcedores. De forma geral, os dirigentes parecem reconhecer a importância da comunicação como uma maneira de incentivar e entusiasmar os torcedores para que possam se envolver com o clube. Não se observa, entretanto, na fala dos Diretores, o papel de mídias sociais como estratégia de comunicação. Isso leva a perceber que eles ainda se mantém alicerçados a canais tradicionais, como o uso do rádio.

\subsection{Eixo temático IX: Identificar e explicar estratégia de relacionamento com sócios}

\section{Quadro 10}

\section{Estratégias de relacionamento com sócios}

\begin{tabular}{|c|c|}
\hline \multirow{3}{*}{$\begin{array}{l}\text { Estratégia de } \\
\text { relacionamento com } \\
\text { sócios }\end{array}$} & $\begin{array}{c}\text { "[...] são várias as promoções que são feitas justamente pra que o sócio tenha algum } \\
\text { benefício" (Diretor de Marketing do Clube A). }\end{array}$ \\
\hline & "[...] a gente não tem o que oferecer para o sócio" (Diretor de Futebol do Clube B). \\
\hline & $\begin{array}{c}\text { "[...] para os sócios a gente procura trazer alguns benefícios, como venda de } \\
\text { ingresso antecipado" (Diretor do Clube C). }\end{array}$ \\
\hline
\end{tabular}

Fonte: Dados da pesquisa.

O dirigente do Clube A afirmou que oferece alguns benefícios aos sócios, como sorteios de camisas e bonés em dia de jogos, participação em eventos comemorativos, local privilegiado no estádio, entre outros. O Clube B, por sua vez, não parece possuir uma estratégia de engajamento de torcedores, sendo, assim, negligenciados. O diretor do Clube C, por sua vez, apresentou a oferta de benefícios, porém se restringe à compra de ingressos facilitada. Em distinção ao Clube $\mathrm{A}$, os demais parecem não ter clara a concepção dos sócios enquanto elementos centrais do clube, o que demonstra uma miopia quanto ao potencial de tais membros. Logo, o marketing do esporte ainda se apresenta aquém do idealizado, visto que, indo de encontro ao que aponta Chadwick (2005) acerca da relevância das partes interessadas, o alinhamento entre os clubes e os stakeholders, como os sócios e patrocinadores, parece não ser o ponto central dos clubes. 
Bezerra, A. R. N., Anjos Neto, M. R., Campos, P. O., \& Costa, M. F. (2021, set./dez.). Estratégias de marketing Esportivo de clubes de futebol do Agreste Pernambucano

\section{Conclusão}

A indústria do esporte é uma das principais influências na economia e no PIB do Brasil. Apesar de sua notória relevância, a gestão do esporte realizada pelos clubes, especialmente do Nordeste do país, parece ainda incipiente e fragmentada mesmo mediante organizações esportivas consolidadas, como clubes de futebol do Agreste de Pernambuco. Muito embora esse fenômeno seja notado, a literatura não o tem endereçado de forma efetiva, o que abre uma lacuna para explorar como se dá o marketing esportivo de clubes consolidados nesta região. Por meio desta pesquisa, empenhou-se esforços para explorar em profundidade as estratégias adotadas a fim de contribuir à literatura do marketing do esporte.

Destaca-se, em primeira instância, que o objetivo principal foi atingido, visto que se analisou a visão de três diretores responsáveis pela área de Marketing dos clubes. Em síntese, pode-se observar que os clubes se pautam em estratégias tradicionais sem diversificar suas fontes de receitas e sem trabalhar de forma satisfatória suas marcas. Não obstante, percebe-se que os times não buscam uma aproximação com seus torcedores, poucas são as estratégias que visam um maior envolvimento e ações voltadas para o fortalecimento da marca também parecem não existir. O fã enquanto elemento basilar no marketing esportivo não é assim percebido pelos diretores, visto que o foco se concentra nos patrocinadores.

Diferente do que indica a literatura, revela-se aqui que a venda de jogadores não é vista como a principal fonte de renda dos clubes, mas sim como um vislumbre para o fortalecimento. Na perspectiva dos diretores, a pesquisa de mercado, por exemplo, é um instrumento de análise dos oponentes, sendo seu papel enquanto uma estratégia para ofertar produtos e atração de novos torcedores deixado de lado. Embora o setor de marketing do Clube A seja gerenciado por um diretor especializado, os outros clubes possuem essa área presidida por um diretor de futebol e administrativo, o que ressalta a fragilidade dos clubes quanto a gestores de esporte habilitados para conduzir estratégias de marketing mais efetivas. Nesse sentido, a exposição de tais fragilidades leva a contribuições gerenciais para os clubes do contexto estudado, especialmente quanto à necessidade de fortalecimento da relação com os torcedores.

Apesar de contribuir à literatura ao explorar em profundidade o marketing esportivo em um contexto local, esta pesquisa apresenta algumas limitações que precisam ser consideradas. Primeiro, uma restrição se refere à condição de generalização, uma vez que, a técnica de estudo de caso permite o conhecimento em profundidade de aspectos pertinentes ao marketing esportivo, entretanto, inviabiliza a extensão das descobertas para outras agremiações ou 
Bezerra, A. R. N., Anjos Neto, M. R., Campos, P. O., \& Costa, M. F. (2021, set./dez.). Estratégias de marketing Esportivo de clubes de futebol do Agreste Pernambucano

modalidades. Além disso, os sujeitos foram selecionados por conveniência, uma vez que os clubes foram selecionados de acordo com o tempo e disponibilidade de acesso.

Como sugestões para futuros trabalhos, recomenda-se a realização da exploração do fenômeno em outros clubes. Haja vista que o fã se apresentou como subjacente às estratégias dos clubes, contribuições à literatura podem emergir a partir de investigações que busquem explorar a visão deles quanto aos clubes que são associados. Isso pode oportunizar entender melhor a relação clube-torcedor mesmo mediante poucas estratégias de engajamento por parte dos clubes. Pode-se conduzir ainda pesquisas que analisem a percepção de patrocinadores sobre o uso do marketing no esporte e a sua relação com os clubes patrocinados.

\section{Referências}

Bardin, L. (1977). Análise de Conteúdo. Lisboa: Portugal.

Bastos, F. C. (2016). Gestão do esporte no Brasil: Reflexões sobre avanços, limites e desafio. (Habilitation Thesis, Escola de Educação Física e Esporte, Universidade de São Paulo). https://doi.org/10.11606/T.39.2019.tde-17062019-123621

CBF. (2019). Impacto do futebol brasileiro. Retrieved from https://conteudo.cbf.com.br/cdn/201912/20191213172843_346.pdf. Accessed at: 31 de jan. 2020.

Chacko, J. M., \& Wagers, L. K. (1999). Major leagues sports marketing in North America and its emergence internationally. Journal of Professional Services Marketing, 20(1), 81-98. https://doi.org/10.1300/J090v20n01_07

Chadwick, S. (2005). Sport marketing: A discipline for the mainstream. International Journal of Sports Marketing and Sponsorship, 7(1), 7. https://doi.org/10.1108/IJSMS-07-012005-B001

Chelladurai, P. (2009). Managing organizations for sport and physical activity. (3rd. ed.). Scottsdale: Holcomb Hathaway.

Chun, E., Ko, J., Lee, J., \& Ko, E. (2013). The effect of sports event tourism on event attitude and the brand equity of sportswear sponsors. Journal of Global Scholars of Marketing Science, 23(1), 72-91. https://doi.org/10.1080/21639159.2012.744512

Ciomaga, B. (2013). Sport management: A bibliometric study on central themes and trends. European Sport Management Quarterly, 13(5), 557-578. https://doi.org/10.1080/16184742.2013.8382837

Costa, M. F., Costa, C. E., Angelo, C. F., \& Moraes, W. F. A. (2018). Perceived competitive advantage of soccer clubs: A study based on the resource-based view. RAUSP Management Journal, 53, 23-34. https://doi.org/10.1016/j.rauspm.2016.08.001 
Bezerra, A. R. N., Anjos Neto, M. R., Campos, P. O., \& Costa, M. F. (2021, set./dez.). Estratégias de marketing Esportivo de clubes de futebol do Agreste Pernambucano

Dabscheck, B. (2015). Football in Asia: History, culture and business / soccer in Brazil / soccer in the Middle East. The International Journal of the History of Sport, 32(9), 1205-1211. https://doi.org/10.1080/09523367.2015.1066967

Ferreira, B. R. T., \& Leão, A. L. M. S. (2018). Dois espaços mágicos? O estádio dos aflitos e a arena Pernambuco sob o olhar da Antropologia da Supermodernidade de Marc Augé. Revista de Administração da UFSM, 11(4), 980-998. https://doi.org/10.5902/1983465917454

Fink, J. S. (2013). Theory development in sport management: My experience and other considerations. Sport Management Review, 16, 17-21. https://doi.org/10.1016/j.smr.2011.12.005

Fortunato, J. A. (2017). The FIFA crisis: Examining sponsor response options. Journal of Contingencies and Crisis Management, 25(2), 68-78. https://doi.org/10.1111/14685973.12125

Fullerton, S., \& Merz, G. R. (2008). The four domains of sport marketing: A conceptual framework. Sport Marketing Quarterly, 17(2), 90-107. https://commons.emich.edu/mktg_facsch/26/

Gil, A. C. (2002). Como elaborar projetos de pesquisa. (4th. ed.). São Paulo: Atlas.

Haugaasen, M., \& Jordet, G. (2012). Developing football expertise: A football-specific research review. International Review of Sport and Exercise Psychology, 5(2), 177201. https://doi.org/10.1080/1750984X.2012.677951

Liang, Y. (2017). Marketization impact on the relationships between supporters and football clubs. International Journal of the History of Sport, 34(17-18), 1835-1853. https://doi.org/10.1080/09523367.2017.1341873

Manoli, A. E. (2018). Sport marketing's past, present and future: An introduction to the special issue on contemporary issues in sports marketing. Journal of Strategic Marketing, 26(1), 1-5. https://doi.org/10.1080/0965254X.2018.1389492

McDonagh, P. (2017). Football-marketplace icon? Consumption Markets and Culture, 20(1), 7-11. https://doi.org/10.1080/10253866.2016.1163944

Melo Neto, F. P. (2000). Marketing de Patrocínio. Rio de Janeiro: Sprint.

Mullin, B. (1983). Sport marketing, promotion and public relations. Amherst, MA: National Sport Management.

Mullin, B., Hardy, S., \& Sutton, W. (2007). Sport marketing. (3rd ed). Champaing: Human Kinetics. 
Bezerra, A. R. N., Anjos Neto, M. R., Campos, P. O., \& Costa, M. F. (2021, set./dez.). Estratégias de marketing Esportivo de clubes de futebol do Agreste Pernambucano

Parkhouse, B. L., \& Ulrich, D. O. (1979). Sport management as a potential cross-discipline: A paradigm for theoretical development, scientific inquiry, and professional application. Quest, 31(2), 264-276. https://doi.org/10.1080/00336297.1979.10519943

Pitts, B. G. (2001). Sport management at the millennium: A defining moment. Journal of Sport Management, 15, 1-9. https://doi.org/10.1123/jsm.15.1.1

Ratten, V., \& Ratten, H. (2011). International sport marketing: Practical and future research implications. Journal of Business and Industrial Marketing, 26(8), 614-620. https://doi.org/10.1108/08858621111179886

Reale, G., \& Dalmoro, M. (2019). Passion and market: The intertwining that makes the marketization of brazilian spectacle football. Brazilian Journal of Marketing, 18(4), 97-115. https://doi.org/10.5585/remark.v18i4.16385

Rocha, C. M, \& Bastos, F. C. (2011). Gestão do esporte: Definindo a área. Revista Brasileira de Educação Física e Esporte, 25, 91-103. https://doi.org/10.1590/S180755092011000500010

Santos, M. A. G. N., Freire, E.S., \& Miranda, M. L. J. (2017). A gestão do esporte como tema de pesquisa: Análise da publicação científica. Motrivivência, 29(50), 183-201. http://dx.doi.org/10.5007/2175-8042.2017v29n50p183

Tsiotsou, R. H. (2016). A service ecosystem experience-based framework for sport marketing. Service Industries Journal, 36(11-12), 478-509. https://doi.org/10.1080/02642069.2016.1255731

Yin, R. K. (2005). Estudo de caso: Planejamento e métodos. (3rd ed.). Porto Alegre: Bookman.

Zeigler, E. F. (1987). Sport management: Past, present, future. Journal of Sport Management, 1, 4- 24. https://doi.org/10.1123/jsm.1.1.4 